\title{
The role of vitamins in the diet of the elderly I. Fat-soluble vitamins
}

\author{
J. Csapó ${ }^{1,2}$ \\ e-mail: csapo.janos@gmail.hu \\ Cs. Albert ${ }^{1}$ \\ e-mail: albertcsilla@cs.sapientia.ro
}

\author{
J. Prokisch ${ }^{2}$ \\ e-mail: jprokisch@agr.unideb.hu \\ ${ }^{1}$ Sapientia Hungarian University of Transylvania, \\ Faculty of Miercurea Ciuc, Department of Food Science, \\ RO-4100 Miercurea Ciuc, Piata Libertăţii 1., Romania \\ ${ }^{2}$ University of Debrecen, Faculty of Agricultural and Food Sciences and \\ Environmental Management, Institute of Food Technology, \\ H-4032 Debrecen, Böszörményi St 138., Hungary
}

\begin{abstract}
Following a discussion on the daily energy and protein requirements of elderly people, the authors will go on to talk about vitamin needs and the role of the four fat-soluble vitamins (A, D, E, and K). They point out that vitamin requirements in old age do not essentially differ from adult people's, but they must take account of the fact that the body's vitamin stores might get filled up, which may reduce vitamin needs, on the one part, but the altered physiological processes may increase them, on the other. Regarding the case of fat-soluble vitamins, reduced fat absorption, decreased vitamin storage capacity of the liver, reduced dietary intake, partial deficiency of digestive enzymes, and absorption disorders in the intestines may all lead to vitamin deficiencies. Problems may also arise due to multiple vitamin overdose developed either as a consequence of overconsumption of vitamin tablets or because
\end{abstract}

Keywords and phrases: vitamin A, vitamin, D, vitamin E, vitamin $\mathrm{K}$, fat-soluble vitamins, vitamin needs, vitamin requirements of the elderly 
the body's vitamin stores are constantly filled up to maximum capacity. Positive and negative changes resulting from the consumption of several times the daily dose recommendations are covered as well. The authors show that $\mathrm{A}, \mathrm{D}, \mathrm{E}$, or $\mathrm{K}$ vitamin deficiency occurs very rarely in the case of a normal diet; however, great care must be taken in order to meet vitamin $\mathrm{D}$ and, simultaneously, calcium requirements so that to avoid osteoporosis and an increased risk of bone fractures in elderly people. The paper discusses the fat-soluble vitamin needs of the elderly and, where necessary, specifies the requirements for men and women separately, while also touching upon those foodstuffs and methods that can contribute to the optimal satisfaction of the elderly people's vitamin needs.

\section{Introduction}

In order for our organism to work properly, we need a regular daily consumption of foodstuffs through which we can get access to vital proteins and energy. As the age increases, especially after 40 years of age, people's energy needs are on the decline (Hallfrisch et al., 1990), and an older person can easily make do with one third less of energy $(9,000-9,500 \mathrm{~kJ} /$ day $)$ than a forty-year-old does (11,000-11,500 kJ/day). In general, we can say that an approx. 70-year-old person can get along with $30 \%$ less energy than a younger individual and that the daily energy intake of $60-80 \%$ of elderly people living in a community is 4,000-4,500 kJ (Mcgandy et al., 1966; Abraham et al., 1977). The second half of the past century saw a decrease of 4,000-5,000 kJ/day and of 3,000 kJ/day in the energy intake of men and women, respectively, which entails a reduced intake of several important nutrients (Thomas, 2007).

The biggest problem lies in the decreased protein intake, since $10 \%$ of men and $20 \%$ of women consume proteins below the level prescribed by the RDA (Recommended Dietary Allowance). Less protein intake means less mineral and vitamin absorption, leading to various deficiency diseases (Wakimoto \& Block, 2001). The vitamin and mineral intake in $50 \%$ of the elderly people does not reach the necessary values specified in the RDA, and thus $10-30 \%$ of the respective population suffers from deficiencies. Elderly people tend to consume less foodstuff rich in calories and they rather resort to calorie-restricted diets consisting of whole grains, vegetables, and fruits, in parallel to which both the amount of dietary intake and fluid consumption are on the decrease. On top of this, all those physiological changes that accompany the aging process, such as slower emptying of the stomach, altered senses of taste and smell, hormonal changes, and mastication difficulties as a result of changes in dentition, make 
their contribution to this.

Reduced food and energy intake is also closely related to negative changes in terms of income, the education level of those affected, changes in the family and socio-economic status, as well as opinions, beliefs, and misbeliefs regarding foodstuffs. Consequently, reduced calorie and nutrient intake lead to dietaryrelated deficiency diseases. First of all, those elderly people are at risk who consume a vitamin-deficient diet, are vegetarians, or suffer from some foodingredient-related malabsorption. Particular attention should be paid to those suffering from lactose and milk protein intolerance as they cut themselves off from sources of high biological value protein and the highly beneficial milk fat (Drewnowski \& Shultz, 2001).

In the majority of the world's countries, healthcare authorities determine for all age-groups the necessary minimum values of calories and food ingredients that are indispensable for a healthy lifestyle, expressed in RDA levels. They took account of body weight, stage of development (child-adult), and gender (male-female), but no distinction was made between individuals having the same body weight but belonging to different age-groups. Officially determined RDA levels have gone through continuous changes, but later on they also took into consideration the fact that the human organism is capable of stockpiling certain nutrients that it can put to work in cases of malnutrition. They also established that the long-term effects of foodstuffs consumed for therapeutic purposes in quantities above the average is controversial (Thomas, 2007).

In an attempt of doing away with the errors of the RDA, they introduced the DRI (Dietary Reference Intake), which did not only take account of nutrition requirements but it also reckoned with disease prevention. On the 'design table', it was considered a basic requirement that the determined values should fully satisfy the needs of $50 \%$ of the population, whereas $98 \%$ should not suffer from any deficiency diseases in regard to nutrients without an RDA value. They determined the appropriate intake values and the upper limits that could still be tolerated and did not cause any risk in $98 \%$ of the population. RDI includes the senior population over 70 years of age, paying separate attention to men and women. Table 1 shows the RDI values of fat-soluble vitamins and the tolerable upper limits (Thomas, 2007).

If we compared the data provided in the table with values determined for the younger population, only slight differences could be observed. 
Table 1: RDI values of fat-soluble vitamins for the male and female population over 70 years of age and the tolerable upper limits

\begin{tabular}{cccc}
\hline Vitamin & Men & Women & Upper limit \\
\hline Vitamin A $(\mu \mathrm{g})$ & 900 & 700 & 3,000 \\
Vitamin D $(\mu \mathrm{g})$ & 15 & 15 & 2,000 \\
Vitamin E $(\mathrm{mg})$ & 15 & 15 & 1,000 \\
Vitamin K $(\mathrm{mg})$ & 120 & 90 & No data \\
\hline
\end{tabular}

\subsection{Macronutrient requirements}

For an optimal bioavailability of vitamins, the human organism needs an appropriate supply of energy, proteins, fat, and carbohydrate. Daily calorie requirements for sedentary activities were determined at $100-110 \mathrm{~kJ} / \mathrm{kg} /$ day, while the corresponding values were assigned in the range of $160-170 \mathrm{~kJ} / \mathrm{kg} /$ day for elderly people living under normal conditions. There are different formulae scientists apply in practice to assess energy requirements (Ireton-Jones, 1989). Protein requirements are $0.8 \mathrm{~g} / \mathrm{kg} /$ day (NRC, 1989), but if we wish to establish a positive nitrogen balance in older people, then this value is 1.0-1.2 $\mathrm{g} / \mathrm{kg} /$ day (Campbell et al., 2001). People more advanced in age have need of proteins because the essential amino acids found therein are the very construction bricks of the proteins and of various, biologically valuable components in their organism. Assuring an optimal supply of energy and proteins is fundamental as, for lack of energy, the organism will not be capable of building the absorbed amino acids into the body, and it will make use of them to obtain more energy.

The optimal carbohydrate intake responsible for $50-60 \%$ of the organism's energy requirements is highly essential as a great part of them is utilized as energy source, protecting proteins from degradation and their utilization in gluconeogenesis. An insufficient amount of energy and carbohydrate intake leads to muscle atrophy since proteins are thus utilized as energy, and they will degrade together with subcutaneous tissues. Whole-grain breads, cereals, legumes, vegetables, fruits, and milk all contain a sufficient amount of carbohydrates (Thomas, 2007).

Fat is the most energy-dense nutrient, stored in the organism in the form of triglyceride in the adipose tissue. The optimal amount of energy via fat intake is $20-25 \%$, which can be occasionally much higher, resulting in obesity. There are no recommended doses for fat intake, but there is proof that fats with a 
balanced fatty acid composition (oil seeds, poultry, fish, and vegetables) are much healthier as they contain a sufficient amount of essential fatty acids as well.

Besides calories and proteins, dietary fibres - originally part of our foodstuffs - are essential components of our foods, just as added fibres, both being indigestible substances but with several beneficial effects. Fibre content is beneficial to health, playing a prominent part in reducing the symptoms of failures of the cardiovascular system and preventing events of stroke and certain types of cancer. A clear association was found between high fibre consumption and a low incidence rate of cardiovascular diseases, in particular in cases when cereals, fruits, or vegetables served as fibre sources, though we also know of such experiments where this relationship was inconclusive (Wolk et al., 1999; Steffen et al., 2003). Several researchers revealed a correlation - while some others did not - between colon cancer and fibre consumption. It has been a well-known fact that as fibres swell up they help the movement of faecal matter, prevent constipation, and on a large area bind excess bile acids as well as other, undesirable substances entering the body (Park et al., 2005). The optimal daily fibre intake for men is $38 \mathrm{~g} /$ day and for women $25 \mathrm{~g} /$ day. Since fibre content is difficult to digest and it also reduces the bioavailability of other nutrients, over 50 years of age, the optimal amount is $30 \mathrm{~g} /$ day for men and $21 \mathrm{~g} /$ day for women.

On the whole, there are no significant differences between the DRI values recommended for the macronutrient components in respect of age-groups over 50 years. Recommended daily water intake for men is $3.7 \mathrm{l}$ and for women $2.7 \mathrm{l}$. Daily carbohydrate intake was determined at $130 \mathrm{~g}$, protein intake (calculated at $0.8 \mathrm{~g} / \mathrm{kg} /$ day) at $56 \mathrm{~g}$ for men and $46 \mathrm{~g}$ for women, while fibre intake at 30 $\mathrm{g}$ for men and $21 \mathrm{~g}$ for women (Thomas, 2007).

\section{Vitamin requirements}

For the preservation of human life, we also need certain natural organic compounds in small quantities that play a role in the control of metabolism and energy metabolism as well as in the regeneration of the body. These essential substances are the vitamins. They are such organic compounds that the human body cannot - at least not sufficiently - synthesise, they do not provide energy, but they are indispensable for metabolism and energy flow.

The effect of vitamins is based on the fact that acting as catalytic or regulatory factors in different parts of the organism they get involved in the phys- 
iological processes. Some vitamins become bound to proteins, and take part in biochemical processes as enzymes, while another group of them performs a crucial role in protein synthesis. Daily vitamin requirements are dependent on age, state of health, and nature of the work performed. Humans get access to the necessary vitamins by consuming foods of plant and animal origin, while some vitamins can be obtained with the help of microorganisms living in the intestinal tract (Csapó \& Csapó-Kiss, 2002).

It has been assumed that fat-soluble vitamins regulate the biosynthesis of certain proteins. In their absence, enzyme activity will either decrease or increase in certain tissues. The organism is able to store fat-soluble vitamins, wherefore related cases of avitaminosis are much rarer, but there is a higher risk of hypervitaminosis regarding, first of all, vitamins A and D.

In older people, lower levels of energy and protein intake often go hand in hand with inadequate vitamin supply, especially when combined with insufficient vegetable and fruit consumption. About $50 \%$ of the elderly consume vitamins below the prescribed RDA levels, while $10-53 \%$ of them hardly reach the desired levels (Foote et al., 2000; Souba, 1997), which is also due to the fact that only $10 \%$ of them consume vegetables and fruits regularly, on a daily basis. According to a survey, $41 \%$ of the elderly people do not consume fruits on a daily basis, while $17 \%$ of them do not consume vegetables regularly (Block, 1991). Vitamin A deficiency has been observed only occasionally despite a decreased consumption. However, vitamin D deficiency is affecting 3-7\% of the elderly population, which in extreme cases, in retirement homes, can reach as high as $35 \%$. As in old age body fat increases, the organism can easily store fat-soluble vitamins, making their daily intake unnecessary.

Nevertheless, the organism does not dispose of such storage levels in terms of water-soluble vitamins, which is why vitamin $\mathrm{B}$ - except for vitamin $\mathrm{B}_{12}$ stored in the liver - requirements have to be met on a daily basis. Consequently, vitamin deficiencies were observed in 13-43\% of the elderly for vitamin $\mathrm{B}_{1}$ and in 5-56\% for vitamin $\mathrm{B}_{6}$ (Hajjar \& Pharm, 2007). Such typical cases of vitamin deficiency diseases as scurvy, beriberi, or pellagra have a very low incidence rate among the senior population. Vitamin deficiencies tend to be symptomatic in cases of insufficient consumption of foods in terms of quantity and quality or when people refuse to consume certain types of food on a whim (Gordon, 1993).

The importance of an adequate supply of vitamins is also confirmed by scientific research pointing out the vitamins' efficiency against free radicals responsible for the development of certain diseases and known to be associated with ageing. The idea was initially received with scepticism but after 
all accepted, thus foregrounding the consumption of vitamins with antioxidant properties. It has become common practice to consume vitamins with antioxidant properties in doses way above physiological levels in order to prevent diseases and treat chronic diseases. Patients were encouraged to consume large quantities of vitamins as these would help prevent cardiovascular diseases and cancer. Pauling (1993) was one of the pioneers of this theory, supporting the idea that the consumption of large amounts of vitamin $\mathrm{C}$ helps in slowing down the ageing process.

Considering the range of vitamin preparations developed in the past few years, elderly people paying due attention to their alimentation do not have to reckon with vitamin deficiency. Therefore, people consuming vitamin-deficient foods can also gain access to vitamin supplies by the regular consumption of vitamin supplements (Hajjar \& Pharm, 2007).

\section{Fat-soluble vitamins}

Generally speaking, our organism has A, D, E, and K vitamins stored up, which is why in case of malnutrition they will leave our body at a very slow pace. With age, storage levels for fat-soluble vitamins can even reach the threshold values of hypervitaminosis.

\subsection{Vitamin A}

Vitamin A deficiency causes nyctalopia, also known as night-blindness, which gave it the name of 'epithelium-protector' vitamin, necessary for keeping the skin and the mucous membrane intact, protecting the organism from invaders coming through these surfaces. The most severe symptom of vitamin A deficiency is blindness, which occurs consequent upon the drying out of the cornea. In its absence, a reduced immune activity sets in, the white blood cell count decreases, and an increased susceptibility develops to pneumonia and respiratory diseases. In terms of the organism, this is a growth factor since its deficiency slows down the development of bones in young people. Hypervitaminosis leads to loss of hair, inflammation of the skin resulting in peeling, and pain in the extremities.

Plants contain only the provitamins of vitamin A. Vitamin $A_{1}$ may be formed from approx. 12 types of carotenoid compounds, out of which $\alpha_{-}^{-}, \beta-$, and $\gamma$-carotene as well as cryptoxanthin are the most important ones. Among our foodstuffs, cod-liver oil, chicken-, pork-, and goose-liver all abound in vitamin $\mathrm{A}$, whereas egg, milk, and dairy products may also have a consider- 
able amount of vitamin $\mathrm{A}$ in store. Carrot, rhubarb, and spinach are rich in $\beta$-carotene.

Bioavailability of vitamin A, but especially of carotenes, is more efficient in the presence of fats. Upon the consumption of raw vegetables, only about $2 \%$ of the carrot's carotene content gets absorbed, while the rest is eliminated along with the faecal matter. In the human organism, carotenoids are enzymatically transformed into vitamin $\mathrm{A}$, and are stored in the liver as vitamin $\mathrm{A}_{1}$ fatty acid esters. They fight off the invasion of free radicals and, acting as excellent antioxidants, protect oxidation-sensitive food ingredients as well as the membranes in our body from oxidation and degradation.

Vitamin A is absorbed through the epithelial cells of the small intestine, and is transported through the lymphatic system to the liver, where the organism stores it up. The liver contains 50-95\% of the body's vitamin A content. The vitamin A level of the blood is highly controlled, wherefore it is only marginally affected by vitamin A intake and its level is barely conducive to the vitamin A balance of the organism, given that vitamin A level in the blood is mostly dependent on the extent of the vitamin released from the liver (Hajjar \& Pharm, 2007).

Contrary to vitamin A, carotenes are absorbed from the small intestine through passive transport, and transformed at first into vitamin A aldehyde in the epithelial cells, and then via reduction into vitamin A alcohol, ending up in the liver, where they are stored up. Apart from the liver, carotenoids can be stored up in human tissues such as adrenal glands and the adipose tissue. Lycopene can be found mostly in the testicles, while the oxygenated carotene derivatives (zeaxanthin, lutein) are mostly located in the macula lutea, or yellow spot, which is free of $\beta$-carotene (Hajjar \& Pharm, 2007).

The daily vitamin A requirement of humans is $0.8-1.5 \mathrm{mg}$ of vitamin A and $5-9 \mathrm{mg}$ of $\beta$-carotene. Over 50 years of age, this value decreases to 700 $\mu \mathrm{g} /$ day for men and $900 \mu \mathrm{g} /$ day for women. Developed countries register very few cases of deficiency diseases among the elderly population. If it does occur, however, some other reasons may lie behind, such as reduced fat absorption, other anomalies, liver problems (its incapability of storing up vitamin A), decreased dietary intake of vitamin A, or its increased excretion via the kidney (Hajjar \& Pharm, 2007).

An examination of elderly people aged $65-75$ years concluded that with the passing of the years the vitamin A content of the liver does not show any decrease (Hoppner, 1968), but the amount of vitamin A released from the 'depository' does decrease, giving rise to the occurrence of toxicity events (Krasinsky et al., 1989). We must take account of hypervitaminosis if our regular, daily 
vitamin intake exceeds $3,000 \mu \mathrm{g}$, which is three-four times the recommended value. The malfunctioning of the kidney or liver increases the possibility of toxicity, which can be partly compensated with vitamin E. Hypervitaminosis A in the elderly may cause pain in the bone, osteitis, and hypercalcemia as vitamin $\mathrm{A}$ - developing a negative calcium balance - increases vitamin $\mathrm{D}$ activity and parathyroid-hormone activity. This decreases bone mineral density and increases predisposition to bone fractures (Kneissel et al., 2005; Rohde \& Deluca, 2003).

Carotene deficiency is practically inexistent and there is no RDA value in this respect. Carotene is not considered a toxicant, and there is no record ever of a high intake of carotene to cause any sort of disease as well as no proof of a large amount of carotene, transformed into vitamin A, leading to any adverse effects. Nevertheless, overconsumption of carotene is not desirable as it causes people to have a slightly yellowish skin (Mathews-Roth, 1986).

\section{$3.2 \quad$ Vitamin D}

Vitamin D (calciferol) controls the absorption of calcium and phosphor as well as regulates their incorporation into the bones. Sufficient exposure to sunlight in the case of adults makes vitamin D supplementation unnecessary. The various forms of vitamin $\mathrm{D}$ are produced from provitamins ergosterol of plant origin (ergocalciferol, vitamin $\mathrm{D}_{2}$ ) and 7-dehydrocholesterol of animal origin (cholecalciferol, $\mathrm{D}_{3}$ ), upon exposure to UV radiation. Ergosterol can be found in larger quantities in foodstuffs of plant origin, in yeast, certain mushrooms, and ergot. 7-dehydrocholesterol is a steroidal compound present as a cholesterol accompaniment in the subcutaneous fat.

These two forms have been known to be functioning the same way in the body, but Armas et al. (2004) showed that vitamin $\mathrm{D}_{3}$ is three times as effective as $\mathrm{D}_{2}$. Vitamin $\mathrm{D}$ from both sources attaches to the vitamin Dbinding protein, and, carried together to the liver, is hydroxylated into 25hydroxy vitamin $\mathrm{D}$ (calcidiol), which is further hydroxylated in the kidney into 1.25-dihydroxy vitamin $\mathrm{D}$ (calcitriol). Calcitriol is the most active form among them, with a 1,000 times higher affinity to nuclear receptors than calcidiol. The half-life of calcitriol in the body is $4-6$ hours, whereas that of the calcidiol is three weeks (Thomas \& Demay, 2000).

Daily vitamin D requirement up to 20 years of age is $10 \mu \mathrm{g}$, while for adults, except for expectant and nursing mothers, is $5 \mu \mathrm{g}$. An accurate assessment of needs is difficult to make as vitamin is constantly produced in the body, on the skin surface, whenever exposed to sunlight. Large amounts of vitamin D can 
be found in caviar, salmon, butter, chicken-, goose-, pork-, and beef-liver. Our daily foodstuffs contain first of all provitamins, the largest amount of which can be found in milk, butter, liver, and egg yolk (Hajjar \& Pharm, 2007).

Vitamin D deficiency is common among the elderly population and it may cause serious health problems. The most severe issues are related to advanced cases of osteoporosis and an increased probability of bone fractures. Despite that our body can store up vitamin $\mathrm{D}$, as we age, the storage level of both vitamins $\left(D_{2}, D_{3}\right)$ decreases in the blood serum. $25 \%$ of the elderly population living in retirement homes has shown symptoms of vitamin D deficiency, but this number can go up as high as $80 \%$ in cases of long-term stay. Most probably, the lack of exposure to direct sunlight may be held responsible for this, leading to a decrease in the skin's 7-dehydrocholesterol content, of which vitamin $\mathrm{D}$ is produced in the organism of young people. As synthesis in the skin is suppressed, the vitamin D content of the foodstuffs gains a crucial importance in terms of supply. This becomes particularly dangerous when the ratio of milk, dairy products, and other foodstuffs having a high vitamin D content decreases in the nutrition of elderly people. Reduced hydroxylation in the liver and kidney as well as a reduced absorption induced by drug treatments can also contribute to vitamin $\mathrm{D}$ deficiency.

Consequent upon these, the elderly need more vitamin $\mathrm{D}$ compared to the younger population. The optimal daily intake for the 51-70 age-group is 10 $\mu \mathrm{g}$, for those over 70 years, this quantity is $15 \mu \mathrm{g}$, while for severely vitamindeficient individuals $20 \mu \mathrm{g}$ is the recommended amount so as to increase bone mineral density and reduce the risk of bone fractures. This level can be easily attained if multivitamin tablets are administered twice a day or with nutritional supplements rich in vitamin D content. Parallel to vitamin D supplementation, it is highly expedient to apply calcium supplementation as well because the nutrition of the elderly rarely reaches the required level (Kamel \& Hajjar, 2003). Therefore, most vitamin D preparations also contain 200-600 mg of calcium.

The beneficial effect of vitamin $\mathrm{D}$ supplementation in the elderly has been demonstrated by way of clinical experiments too. In an 18-month-long experiment, a supplementation of $20 \mu \mathrm{g}$ of vitamin D and 1,200 $\mathrm{mg}$ of calcium resulted in a significantly reduced probability of hip-bone (43\% less) and other bone (32\% less) fractures as compared to control. Bone mineral density increased by $2.7 \%$ in the thighbone, while this value showed a $4.6 \%$ decrease in those treated with placebo (Chapuy et al., 1992). Based on results, it is recommended that risk groups, such as elderly people, take at least 10-15 $\mathrm{g}$ g of vitamin D and 800-1,000 mg of calcium per day for a balanced calcium content 
in the organism and for the development of an adequate bone strength. Higher doses of vitamin D supplementation $(250-2,500 \mu \mathrm{g})$ per year administered by injection is not recommended by most (Holick, 1994).

During an experiment with elderly, frail women, $20 \mu \mathrm{g}$ of vitamin D supplementation combined with 1,200 $\mathrm{mg}$ of calcium reduced the number of falls by $49 \%$ as compared to the group given only calcium supplementation, what could be explained with an improved functioning of the musculoskeletal system (Gloth et al., 1995). Most experiments led to the conclusion that vitamin D supplementation had reduced the number of falls by $20 \%$ (Bischoff-Ferrari et al., 2004).

The toxic effect of vitamin D in individuals consuming large quantities thereof over a long period of time can occur in very rare cases. For this to happen, however, people would have to consume 50-100 times the optimal daily dose, which would then lead to hypercalcemia, an increased level of calcium in the serum and urine (Johnson et al., 2002). Excessive sunbathing combined with an optimal vitamin D intake can never lead to vitamin D intoxication.

\section{$3.3 \quad$ Vitamin E}

The various forms of vitamin E (tocopherols, tocotrienols) are antioxidant compounds in the protection of essential fatty acids and membrane lipids from oxidation. For this effect, the hydroxyl group found on the aromatic ring is responsible. Besides the antioxidant effect, it suppresses the synthesis of the leukotrienes, through which, acting as a lipoxygenase inhibitor, it has an anti-inflammatory action on the body. Its consumption in larger doses modifies the synthesis of prostaglandins, thus inhibiting platelet aggregation. It also has free-radical scavenging capacity, upon which it can regenerate helped by vitamin $\mathrm{C}$, and then take effect repeatedly. Vitamin $\mathrm{E}$ reduces vascular permeability and influences collagen formation (Hajjar \& Pharm, 2007).

As a fat-soluble compound, it is absorbed from the intestines as chylomicron micelles formed by bile acids. It is released in the bloodstream, induced by lipoprotein lipase, and it gets through to the liver with the help of various transport processes - from here, it finds its way back into the bloodstream under the form of very-low-density lipoprotein. $90 \%$ of it is stored in the adipose tissue, although cell membranes and the lipoproteins circulating in the bloodstream also have the necessary binding capability.

In human nutrition, $\alpha-, \beta-, \gamma-$, and a $\delta$-tocopherols have practical relevance (Csapó \& Csapó-Kiss, 2002). Among them, $\alpha$-tocopherol has the highest biological activity, though $\gamma$-tocopherol is the most wide-spread in foodstuffs. 
Therefore, RDA values for vitamin $\mathrm{E}$ are expressed in $\alpha$-tocopherol equivalents. Due to stereoisomerism, natural $\alpha$-tocopherol gets absorbed more efficiently and its activity is higher than that of its synthetic counterpart.

The natural occurrence of tocopherols is related to plants alone. They are oils of yellowish colour that dissolve only in fats and degreasing agents. The oxidative effect causes them to become compounds with sensitive and reducing properties; therefore, losing their biological activity, they degrade when exposed to air and direct sunlight. They can be used as antioxidants since they are able to inhibit the autoxidation of fatty acids, wherefore their presence delays the rancidity of fats.

$\gamma$-, and $\delta$-tocopherols have the highest antioxidant effect. Humans' daily vitamin $\mathrm{E}$ requirement is $15 \mathrm{mg}$ - it is assumed that the amounts of unsaturated and polyunsaturated fatty acids from dietary intake proportionally increase vitamin E requirements. Especially large quantities of vitamin E can be found in the seeds of legumes, the germ oil of cereal grains, butter, and leafy vegetables. E-avitaminosis or -hypovitaminosis has never been shown in humans.

In old age, vitamin E deficiency would occur only in cases of malabsorption of fats, pancreatic problems, enteritis, or coeliac disease. In these circumstances, vitamin E deficiency can lead to a whole range of aetiological diseases, such as anaemia caused by the increased haemolysis of erythrocytes, slow coagulation, and a multitude of neurological disorders, where vitamin E deficiency is only one of the many causes. Although the daily vitamin E requirement of an adult person is $15 \mathrm{mg}$, intake values in the case of elderly people may reach up to 400-800 mg per day without being conducive to diseases. Nevertheless, we must be careful with regular cases of overdose as regular intake of daily quantities exceeding 1,000 mg can lead to muscle weakness, exhaustion, nausea, or diarrhoea. High doses may be accompanied by haemophilia if the patient uses medicinal products containing coumarin or other, anticoagulant substances.

\subsection{Vitamin K}

Vitamin K (phylloquinone) deficiency leads to severe haemophilia appearing first of all in the gastrointestinal tract. The bleeding wounds do not heal up and coagulation does not take place because the liver cannot synthesise an adequate amount of prothrombin, the protein necessary for blood clotting. Human intestinal flora synthesises a sufficient amount of vitamin K, wherefore deficiency cannot occur in a healthy organism. In the largest quantities, 
it can be found in green leaves, spinach, and cabbage, whereas amongst foods of animal origin the liver contains it in high quantities. Plants contain vitamin $K_{1}$, or phylloquinone, while intestinal bacteria synthesise vitamin $K_{2}$, or menaquinone. Both types are necessary for a normal functioning of the body.

The daily vitamin $\mathrm{K}$ requirement for an adult person is $100 \mu \mathrm{g}$, which is covered by the daily vitamin $\mathrm{K}$ synthesis of the nutrients and intestinal bacteria. A continuous intake is required as the vitamin $\mathrm{K}$ reserves of the liver are very low. Vitamin $\mathrm{K}$ is needed for prothrombin synthesis and it acts as cofactor of enzymes such as $\gamma$-glutamyl carboxylase. It is required for the binding of calcium, the activation of pro-coagulant factors, the synthesis of proteins regulating bone calcium content, and for a normal osseous metabolism.

Daily vitamin $\mathrm{K}$ requirement for women over 50 years of age is $90 \mu \mathrm{g}$ and for men is $120 \mu \mathrm{g}$. Irrespective of the fact that the liver is capable of storing only a small amount of vitamin $\mathrm{K}$, as a rule, no deficiencies occur in elderly people in cases of normal, complex nutrition, since foods of both plant and animal origin contain significant amounts of vitamin K. Our organism is capable of recycling vitamin $\mathrm{K}$ and a normal intestinal flora will produce it in significant amounts. Deficiencies in elderly individuals can take place only if the body is seriously traumatized, the patient has undergone a major gastrointestinal surgery, antibiotics are taken regularly over a long period of time, fat indigestion occurs, a drug therapy is under way that renders the absorption of vitamin $\mathrm{K}$ as well as its mechanism of action difficult, and in cases of malnutrition and starvation. Serum vitamin K measurement does not provide sufficient information on the vitamin supply, especially when the details of vitamin intake are not known. In the senior population, as much as 500 times the RDA value did not cause toxic symptoms.

Vitamin K has been recently associated with the formation of healthy bones since the mineral-binding capacity of osteocalcin is in correlation with the vitamin-K-dependent $\gamma$-carboxylation of glutamic acid molecules. The amount of inadequately carboxylated osteocalcin increases with age, which is closely linked to hip fractures in elderly people (Szulc et al., 1993). Small quantities of vitamin $\mathrm{K}$ supplementation reduced the amount of inadequately carboxylated osteocalcin and of the calcium eliminated via urinary excretion (Vermeer et al., 1999). In male and female subjects with an average age of 75 years, small quantities of vitamin $\mathrm{K}$ supplementation have been shown to significantly reduce the probability of hip fractures (Booth et al., 2000). 


\section{Conclusions}

Elderly people can put vitamins to optimal use only in the conditions of a normal energy and protein intake, as enzymes and energy are required for the release and absorption of vitamins from the nutrients as well as for their transport and the related biochemical processes. We may conclude that in the case of optimally nourished elderly people vitamin requirements do not essentially differ from those of the middle-aged adult population, but we must consider that the body's vitamin stores might get filled up, which may reduce vitamin needs, on the one part, but the altered physiological processes may increase them, on the other. Regarding the case of fat-soluble vitamins, reduced fat absorption, decreased vitamin storage capacity of the liver, reduced dietary intake, partial deficiency of digestive enzymes, and absorption disorders in the intestines may all lead to vitamin deficiencies. Problems may also arise due to multiple vitamin overdose developed either as a consequence of overconsumption of vitamin tablets or because the body's vitamin stores are constantly filled up to maximum capacity. The consumption of several times the daily dose is recommended only in cases of special vitamin deficiencies as there is a high risk of overdose, which could result in serious diseases. It appears that A, $\mathrm{D}, \mathrm{E}$, or $\mathrm{K}$ vitamin deficiency occurs very rarely in developed countries in the case of a normal diet; great care must be taken, however, in order to meet vitamin $\mathrm{A}$ and D and, simultaneously with the latter one, calcium requirements so that to avoid osteoporosis and an increased risk of bone fractures in elderly people.

Although the vitamin A content of the liver is constant in elderly people, the efficiency of releasing vitamin A stored in the liver decreases. In the elderly, the consumption of several times the daily dose recommendations may cause pain in the bone, osteitis, and - due to an increased vitamin D activity induced by vitamin A - hypercalcemia, which decreases bone mineral density and increases predisposition to bone fractures.

Vitamin D requirements of the elderly are heavily dependent on the environment as this vitamin is also produced in the skin upon direct exposure to UV radiation, although this synthesis - as a result of changes in lifestyle - is suppressed in the elderly population. In such cases, the D vitamin content of foodstuffs is of paramount importance, and deficiencies can occur if elderly people do not consume milk and dairy products at all or only in small quantities. Changes in biochemical processes (decreased absorption from the intestines, poor efficiency of hydroxylation in the liver and the kidney) may also cause vitamin deficiencies, whereas use of medication may reduce absorp- 
tion as well. Therefore, up to 70 years of age, $10 \mu \mathrm{g}$, whereas beyond this threshold $20 \mu \mathrm{g} /$ day of vitamin D appears to be the optimal dose for elderly people, which is advisable to be combined with $200-600 \mathrm{mg}$ of calcium/day to maintain an appropriate condition of the bones. Besides a similar dose of vitamin, many recommend a daily calcium intake of 1,000-2,000 $\mathrm{mg}$, especially in the case of female individuals, where predisposition to osteoporosis is much higher. Hypervitaminosis is very rare for both vitamins, and it can occur only in extreme cases that involve consumption several times the daily vitamin requirements.

In old age, vitamin $\mathrm{E}$ and $\mathrm{K}$ deficiency almost never occurs in the case of a normal diet. Vitamin E deficiency may occur in cases of malabsorption of fats, pancreatic problems and enteritis, or coeliac disease, consequent upon which a whole range of aetiological diseases (anaemia, coagulation disorders, or neurological symptoms) may develop. We must be careful with regular cases of overdose as they may lead to muscle weakness, exhaustion, nausea, or diarrhoea. As intestinal flora is also a producer of vitamin $\mathrm{K}$, such deficiency would occur only subsequent to a major gastrointestinal surgery. In cases like this, not even multiple vitamin overdose may cause any problem. Daily doses of vitamin $\mathrm{K}$ intake are closely linked to the development of healthy bones, as a mild overdose reduces the number of bone fractures.

\section{Acknowledgements}

The authors express their grateful thanks for the financial support of the University of Debrecen, Faculty of Agricultural and Food Sciences and Environmental Management, Institute of Food Technology, Sapientia Hungarian University of Transylvania, Faculty of Miercurea Ciuc, Department of Food Science, and the Scientific Research Department of Sapientia Foundation.

\section{References}

[1] S. Abraham, M. D. Carrol, C. M. Dresser, Dietary intake of persons 174 years of age in the United States. Advanced data from vital and health statistics of the National Center of Health Statistics. G. Rockville, MD, Public Health Service, (1977) March 30.

[2] L. A. G. Armas, B. W. Hollis, R. P. Heaney, Vitamin D2 is much less effective as vitamin D3 in humans. The Journal of Clinical Endocrinology and Metabolism, 89. (2004) 5387-5391. 
[3] H. A. Bischoff-Ferrari, B. Dawson-Hughes, W. C. Willett, H. B. Staehelin, M. G. Bazemore, R. Y. Zee, J. B. Wong, Effect of vitamin D of falls: a meta analysis. Journal of the American Medical Association, 291. (2004) 1999-2006.

[4] G. Block, Dietary guidelines and results of food consumption surveys. American Journal of Clinical Nutrition, 53. (1991) 356-357.

[5] S. L. Booth, K. L. Trucker, H. Chen, M. T. Hannan, Dietary vitamin K intakes are associated with hip fracture but not with bone mineral density in elderly man and women. American Journal of Clinical Nutrition, 71. (2000) 1201-1208.

[6] W. W. Campbell, T. A. Trappe, R. R. Wolfe, W. J. Ewans, The recommended dietary allowance from protein may not be adequate for older people to maintain skeletal muscle. Journals of Gerontology Series A: Biological Sciences and Medical Sciences, 56. (2001) 373-380.

[7] M. C. Chapuy, M. E. Arlot, P. D. Delmans, P. J. Meunier, Effect of calcium and cholecalciferol treatment for three years of hip fractures in elderly women. British Medical Journal, 308. (1994) 1081-1082.

[8] J. Csapó, Zs. Csapó Kiss, Élelmiszerkémia [Food chemistry], Mezőgazda Kiadó, Budapest, 2004.

[9] A. Drewnowski, J. M. Schultz, Impact of aging behaviours, food choices, nutrition and health status. Journal of Nutrition Health and Aging, 5. (2001) 75-79.

[10] J. A. Foote, A. R. Giuliano, R. B. Harris, Older adults need guidance $\underline{\text { to }}$ meet nutritional recommendations. Journal of the American College of Nutrition, 19. (2000) 628-640.

[11] F. M. Gloth, C. E. Smith, B. W. Hollins, J. D. Tobin, Functional improvement with vitamin D replenishment in a cohort of frail, vitamin D deficient older people. Journal of the American Geriatrics Society, 43. (1995) 1269-1271.

[12] R. Gordon, The alarming history of medicine. St. Martin's Griffin, New York, (1993). 
[13] R. R. Hajjar, Z. N. Pharm, Vitamin disorders. In: J. E. Morley, D. R. Thomas (eds), Geriatric nutrition. CRC Press, Taylor and Francis Group, (2007) 137-178.

[14] J. Hallfrisch, D. Muller, D. Drinkwater, J. Tobin, R. Andres, Continuing diet trends in men: the Baltimore longitudinal study of aging (1961-1987). Journal of Gerontology, 45. (1990) 186-191.

[15] M. F. Holick, McCollum Award Lecture 1994: Vitamin D: new horizon for the $21^{\text {st }}$ century. American Journal of Clinical Nutrition, 60. (1994) 619-630.

[16] K. Hoppner, W. E. Phillips, T. K. Murray, J. S. Campbell, Survey of liver vitamin A stores of Canadians. Canadian Medical Association, 99. (1968) 983-986.

[17] C. S. Ireton-Jones, Evaluation of energy expenditures in obese patients. Nutrition in Clinical Practice, 4. (1989) 127-129.

[18] K. A. Johnson, M. A. Bernard, K. Fundeburg, Vitamin nutrition in older adults. Clinics in Geriatric Medicine, 18. (2002) 860-872.

[19] H. Kamel, R. R. Hajjar, Osteoporosis for the home care physician. II. Management. Journal of the American Medical Directors Association, 5. (2003) 259-262.

[20] M. Kneissel, A. Studer, R. Cortesi, M. Susa, Retinoid induced bone thinning is caused by subperiosteal osteoclast activity in adult rodents. Bone, 36. (2005) 202-214.

[21] S. D. Krasinski, R. M. Russel, C. L. Otradovec, Vitamin A and E intake: relationship to fasting plasma retinol, retinol-binding protein, retinyl ester, carotene and alpha tocoferol levels in the elderly and young adults. American Journal of Clinical Nutrition, 49. (1989) 112120.

[22] M. M. Mathews-Roth, Beta-carotene therapy for erythropoietic protoporphyria and other photosensitive diseases. Biochimie, 68. (1986) $875-884$.

[23] R. B. McGandy, C. H. Barrows, A. Spanias, A. Meredity, J. L. Stone, A. H. Norris, Nutrient intake and energy expenditure in men of different ages. Journal of Gerontology, 21. (1966) 581-587. 
[24] J. E. Morley, D. R. Thomas, Geriatric nutrition. CRC Press, Taylor and Francis Group, (2007) 1-571.

[25] Y. Park, D. J. Hunter, D. Spiegelman, L. Berkvist, F. Berrino, P. A. van den Brandt, J. E. Buring, Dietary fiber intake and risk of colorectal cancer: a pooled analysis of prospective cohort studies. Journal of the American Medical Association, 294. (2005) 2849-2857.

[26] L. C. Pauling, Vitamin C and the common cold. (1970). W. H. Freeman, Retrieved 12 August 2016 - via Open Library. San Francisco (2016).

[27] C. M. Rohde, H. DeLuca, Bone resorption activity of all-trans retinoic acid is independent of vitamin D in rats. Journal of Nutrition, 133. (2003) $777-783$.

[28] W. W. Souba, Nutritional support, New England Journal of Medicine, 336. (1997) 41-48.

[29] L. M. Steffen, D. R. Jacobs, J. Stevens, E. Shahar, T. Carithers, A. R. Folsom, Associations of whole grain, refined-grain, and fruit and vegetable consumption with risk of all-cause mortality and incident coronary artery disease and ischemic stroke: the Atherosclerosis Risk in Communities (ARIC) Study. American Journal of Clinical Nutrition, 78. (2003) 383-390.

[30] P. Szulc, M. C. Chaupy, P. J. Meunier, FERUM undercarboxilated osteocalcin in marker of the risk of hip fractures in elderly women. Journal of Clinical Investigation, 91. (1993) 174-176.

[31] D. R. Thomas, Nutritional requirements in older adults. In: J. E. Morley, D. R. Thomas (eds), Geriatric Nutrition. CRC Press, Taylor and Francis Group, (2007) 103-121.

[32] M. K. Thomas, M. B. Demay, Vitamin D deficiency and disorders of vitamin D metabolism. Endocrinology and Metabolism Clinics of North America, 29. (2000) 611-627.

[33] C. Vermeer, M. H. J. Knapen, K. S. G. Jie, Physiologic importance of extra-hepatic vitamin K-dependent carboxilation reaction. Annals of the New York Academy of Sciences, 669. (1992) 21-33. 
[34] P. Wakimoto, G. Block, Dietary intake dietary patterns, and changes with age: an epidemiological perspective. Journals of Gerontology Series A: Biological Sciences and Medical Sciences. 56. (2001) 65-80.

[35] A. Wolk, J. E. Manson, M. J. Stampfer, G. A. Colditz, F. B. Hu, F. E. Speizer, C. H. Hennekens, W. C. Willett, Long-term intake of dietary fiber and decreased risk of coronary heart disease among women. Journal of the American Medical Association, 281. (1999) 1998-2004. 